RESEARCH NOTE

\section{HIV-1 Isolation from Plasma Specimens}

\section{Costa $/^{+}$, MG Morgado, VGV Santos*, HEC/FIOCRUZ AIDS Clinical Research Group*, V Bongertz}

\author{
Laboratório de AIDS e Imunologia Molecular, \\ Departamento de Imunologia *Hospital Evandro \\ Chagas, Instituto Oswaldo Cruz, Av. Brasil 4365, \\ 21045-900 Rio de Janeiro, RJ, Brasil
}

Key words: HIV-1 - AIDS - isolation - plasma

The human immunodeficiency virus type 1 (HIV-1), ethiologic agent of AIDS, can be detected within weeks to months of exposure. HIV-1 can be isolated from peripheral blood mononuclear cells (PBMC) of HIV-1 infected patients (RW Coombs et al. 1993 J Clin Microbiol 31: 19801986).

The data accumulated up to now indicate that plasma virus levels may be useful to indicate the rate of viral replication in infected people and thus may possibly be of value for prognostic analyses. During acute HIV-1 infection, the frequency of virus isolation and the plasma virus titers are high (ES Daar et al. 1991 N Engl J Med 324: 961-964, DA Cooper et al. 1995 Lancet 1: 537-540). Following initial viremia, however, the viral load in plasma decreases up to more than a 100 fold (Daar et al. loc. cit.). In many cases this reduction in viremia occurs within a period of several weeks and is correlated most probably with the antiviral immune response.

In designing a collaborative project between laboratories and hospitals in different states of Brazil, the difficulty of shipment of fresh blood was discussed. As there is minimal published data on the stability of HIV-1 load markers with respect to

Financial support by the Integrated Programme of AIDS (PIAF) of the FIOCRUZ/MS and the Brazilian National Council for Research (CNPq).

*B Grinszteijn, MCG Galhardo, MRC Guimarães, S Cavalcante, VC Rolla.

${ }^{+}$Corresponding author. Fax: +55-21-280.1589

Received 29 January 1996

Accepted 11 July 1996 sampling, processing and storing conditions, an attempt to isolate virus from frozen plasma aliquotes was carried out.

For the present study, nine adult women, belonging to a cohort of the Evandro Chagas Hospital, were included. All women were infected heterosexually, at between 24 and 37 years of age (mean age: 26.5). Some additional clinical information was available for these patients (see Table). Sample collection dates varied between 2 months and 15 days before starting of the experiment. On receival of blood samples, PBMC were separated by gradient centrifugation and plasma was aliquoted and stored at $-20^{\circ} \mathrm{C}$. Surplus PBMC were cryopreserved.

Isolation of HIV-1 from fresh or frozen PBMCs was carried out using the traditional co-culture method with phytohemmaglutinin (PHA) stimulated normal donor PBMCs (H RuebsamenWaigmann et al. 1994 AIDS Res Hum Retroviruses 11: 1401-1408). For isolation of HIV-1 from plasma specimens, the sediment of $2 \mathrm{ml}$ of plasma (ultracentrifuged 40,000 x g/60 min), resuspended in $0.5 \mathrm{ml}$ of culture medium (RPMI 1640, Sigma, St Louis, USA) was used to infect $5 \times 10^{6}$ PHAstimulated donor PBMCs. The cells were gently resuspended in $0.5 \mathrm{ml}$ of medium and incubated with the samples at $37^{\circ} \mathrm{C} / 5 \% \mathrm{CO}_{2} / 30 \mathrm{~min}$. At the end of the incubation period, $4 \mathrm{ml}$ of culture medium were added. Thereafter, the cultures were maintained just as routine co-cultures (RuebsamenWaigmann et al. loc. cit.). Isolation success was evaluated by HIV-1 p24 antigen determination (HIV-1 p24 Ag detection kit, ELISA, DuPont, Wilmington, DE) in supernatants of the 7 th and 14th day of co-culture.

HIV-1 isolation from plasma was positive from all samples from which HIV-1 had been originally isolated from fresh PBMC (6/6). Isolation of HIV-1 from frozen PBMC was positive for only three out of the four attempts carried out. Three samples from which HIV-1 isolation from fresh PBMC had been negative were also included. Isolation of HIV-1 from frozen PBMC was successful in the attempt carried out, while isolation from plasma samples from three patients were positive in two attempts. These results indicate that a second attempt of HIV-1 isolation from stored materials is worthwhile, and that no significant difference between HIV-1 isolation from plasma or cryopreserved PBMC could be noted.

A number of studies have reported the successful isolation of HIV from cell-free body fluids, including plasma and serum (RW Coombs et al. 1989 $N$ Engl J Med 321: 1626-1630). The frequency obtained of plasma isolation reported was higher in individuals with more advanced disease as indi- 
TABLE

Information on number of patients (No.), date of sampling (Date), clinical classification (Clin. class - according to CDC 1986), period of time between sampling and first positive serologic diagnosis (Time post inf.), number of $\mathrm{CD}^{+}$cells (No. CD4/mm ${ }^{3}$ ), and antiretroviral treatment (Chemotherapy) is indicated for each patient in paralell to viral detection (Days of co-culture)

\begin{tabular}{|c|c|c|c|c|c|c|c|c|}
\hline \multirow{2}{*}{\multicolumn{2}{|c|}{ No./Date }} & \multirow{3}{*}{$\begin{array}{c}\begin{array}{c}\text { Clin. } \\
\text { class }\end{array} \\
\text { II }\end{array}$} & \multirow{3}{*}{$\begin{array}{c}\text { Time } \\
\text { post-inf. } \\
>9 \mathrm{~m}\end{array}$} & \multirow{3}{*}{$\begin{array}{c}\begin{array}{c}\text { No. CD4/ } \\
\mathrm{mm}^{3}\end{array} \\
83\end{array}$} & \multirow{3}{*}{$\begin{array}{c}\text { Chemo- } \\
\text { therapy } \\
\text { Y }\end{array}$} & \multicolumn{3}{|c|}{ Day of p24 detection } \\
\hline & & & & & & \multirow{2}{*}{$\begin{array}{c}\text { Fresh } \\
\text { PBMC } \\
-\end{array}$} & \multirow{2}{*}{$\begin{array}{c}\text { Frozen } \\
\text { PBMC } \\
\text { ND }\end{array}$} & \multirow{2}{*}{$\begin{array}{c}\text { Plasma } \\
14\end{array}$} \\
\hline 1 & Mar 95 & & & & & & & \\
\hline 2 & Feb 95 & II & $>5 \mathrm{~m}$ & NA & $\mathrm{Y}$ & 7 & ND & 14 \\
\hline 3 & Feb 95 & III & $>3 y$ & 600 & Y & 7 & 14 & 14 \\
\hline 4 & Feb 95 & IV & $>2 y$ & 87 & $\mathrm{Y}$ & 7 & ND & 14 \\
\hline 5 & Feb 95 & IV & $>5 \mathrm{~m}$ & 312 & $\mathrm{~N}$ & 7 & 14 & 14 \\
\hline 6 & Feb 95 & III & $>2 y$ & 356 & $\mathrm{~N}$ & 14 & - & 14 \\
\hline 7 & Mar 95 & II & $>2 y$ & NA & $\mathrm{N}$ & 7 & 7 & 14 \\
\hline 8 & Apr 95 & NA & $>7 \mathrm{~m}$ & NA & Y & - & 14 & - \\
\hline 9 & Apr 95 & II & $>1 \mathrm{~m}$ & 308 & $\mathrm{~N}$ & - & ND & 14 \\
\hline
\end{tabular}

NA: not available; ND: not done. Viral antigen detected using HIV-1 p24 ELISA kit (DuPont, Wilmington, DE); $\mathrm{N}$ : no treatment; Y: treatment; PBMC: peripheral blood mononuclear cells.

cated by lower $(<200)$ concentrations of CD4 positive lymphocytes in the peripheral blood $(\mathrm{C}$ Rouzioux et al. 1992 AIDS 6: 373-377, LD Robin et al. 1992 J Acquir Immune Defic Syndr 5: 822828). In this study, only two women had AIDS, but overall CD4 concentrations were quite low. However, our results indicate no specific correlation between phase of disease and of HIV-1 isolation from plasma.

In conlusion, a similar efficiency of recovery of virus from PBMCs (both fresh and frozen) and from plasma was observed. Therefore, it is possible to isolate HIV-1 even if local laboratory facilities prepared for routine procedures in cell cul- ture are not available. An important difference observed between positive isolation of HIV-1 from plasma and PBMCs was the culture period needed for attaining positivity; probably reflecting lower concentration of infectious virus in plasma than in CD4 positive PBMCs. The efficient isolation of HIV-1 from plasma samples described here should be of importance for studies envolving frozen plasma samples stored at sites were efficient collection and storage of PBMCs is not feasable.

Acknowledgements: to Dr Carlos Bonecker, Santa Catarina Center for Haemophiliacs, Rio de Janeiro, RJ, Brazil for availability of blood from HIV-1 seronegative blood donors. 